\title{
Weed Vegetation to Enhance Soil Fertility in Vineyards
}

\author{
M. A. Chupanov, M.-R. A. Kaziev, M. M. Alichaev \\ The Dagestan Research Institute of Agriculture, Makhachkala, Dagestan Republic, Russia \\ Email: chrasul@mail.ru
}

Received 13 June 2014; revised 16 July 2014; accepted 3 August 2014

Copyright ( 2014 by authors and Scientific Research Publishing Inc.

This work is licensed under the Creative Commons Attribution International License (CC BY).

http://creativecommons.org/licenses/by/4.0/

(c) (i) Open Access

\section{Abstract \\ The causes of degradation processes in the fruit-bearing vineyards in the Dagestan Republic were studied. As a result, on the base of the obtained data, a prototype of instrument for the formation of herbal flooring (layer) between the rows of plantings was created.}

\section{Keywords}

\section{Soil, Degradation, Weed Vegetation, Prototype}

\section{Introduction}

In recent years, the condition of the soil in the fruit-bearing vineyards in the Republic of Dagestan has deteriorated. In many farms, the soil is turning into an erosive mass. And it does not allow to obtain a high yield not to mention biologically possible yield.

The main reason for this is the absence of scientifically grounded system of keeping the rows of vineyards and in this regard, the wrong attitude to the soil as one of the most important substances is involved in the formation of the harvest.

At the same time, farms, due to the high cost and their economic situation, can hardly afford the necessary quantity of fertilizers.

Under the influence of running bodies (propulsion) of tractor units, moving many times over the season on the same track (15 - 20 times per season), soil at a depth of $4-5 \mathrm{~cm}$ turns into a mass, with a particle size of less than $0.25 \mathrm{~mm}$-erosive mass (dead layer of soil horizon). This erosion layer of soil by plowing moves in the lower rooting zone layers of the horizon, and from there better structured soil rises to the top. Later, under the influence of propulsion, this layer also becomes erosive etc. So every year, this process is repeated. As a result, on the one hand we have soil unstructurizing and on the other hand, there is a shortage of supply for the root system of plants. 
To prevent degradation processes, by reducing the negative impacts of propulsion units on the soil, evaporation of humidity and providing the organic fertilizers, the system of keeping the rows of vineyards is being developed, and the materials of this article, are its integral part.

One of the elements of this system is the weed vegetation growing in the interrows of vineyards; it is used to create the grass layer but with roots cut. Weed vegetation is considered bad and they are trying to get rid of it. But in this work we seek to use it for the benefit of improving soil fertility. The herbal layer derived from it, prevents the direct contact of wheels units and sunlight with the soil, helps save the moisture in the hot period of time, and then, is used as organic fertilizers for enriching its nutrients and disintegration.

\section{Purpose of Research}

To investigate the reasons of occurrence and to elaborate measures for prevention of these degradation processes in bearing vineyards of the Republic (the example of the state unitary enterprise "Caspian” of Kayakentskiy district).

\section{The Object and Methods}

The area was studied for morphological features and physical characteristics of soils with a description of weeds growing in the interrows of vineyards.

The conducted field experiments were guided by the program and methods according to Branch Standard 10.4.4.99, RD 10.4.2-89.

\section{Results and Discussion}

The examined soils are defined as meadow-salt-clay; on the profile they are deeply dense, bulk weight varies from 1.19 to $1.60 \mathrm{gr} / \mathrm{cm}^{3}$ in the upper layer $\left(0\right.$ to $25 \mathrm{~cm}$ ) and to $1.64 \mathrm{~g} / \mathrm{cm}^{3}$ in the underlaying layers (up to 55 $\mathrm{cm}$ ). The transition density is sharp and clear as in size so in external features of the profile. The root system of the grape-vine is mainly in the upper layer where the density is on average equal to $1.30 \mathrm{~g} / \mathrm{cm}^{3}$. Crop productivity in the region doesn't exceed 45 - 50 metric centers per hectare.

According to V. F. Valkova and other authors for successful development of the root system of plants soil density should not exceed $1.40 \mathrm{~g} / \mathrm{cm}^{3}$ [1] [2]. We believe that a strong puddling is a major constraint to growth, development and yield of grapes.

In our opinion, the vine crop productivity in the examined plots is low because the nutrition, air and heat regimes of soils are violated. As a consequence, the weak root system of the vine cannot provide the aboveground mass with the necessary amount of nutrients and water required for the entire period of active vegetation, especially, for formation the optimal harvest after the flowering. Hot climate and water deficiency in the republic make soil conditions a major factor of successful growth, development and fruiting of vine.

One of the main reasons that lead the soil deterioration to such deplorable state is absence of scientifically-grounded system of keeping rows of vineyards in proper order. And in this regard, our agronomic services don't realize the importance of properly organized sequence of technological operations during crop cultivation and use of vine equipment which must be directed on taking into consideration the climate of the republic. They must be aimed on creation favorable growing conditions for plantations. And as a result we have wrong attitude to soil which is one of the most important substances involved in formation of the harvest. This process results in the gradual soil unstructurizing which is the main reason of low average crop yield in the republic (about 50 to 80 centner/hectare).

To prevent this process a system of complex measures is suggested. They must be agrobiological and technical operations aimed at creating favorable conditions for microorganisms in the soil and root system environment of plants. These activities will lead to soil enrichment with nutrients and its disintegration and as a result, improve the productivity of crops and increase its fruiting term.

The most important of them is use of weeds vegetation growing in interrows of plantations for creating there a herbal flooring (layer). This operation involves several challenges [3] [4]:

Firstly, it is assumed that the weed vegetation is always considered as malware vegetation which feed from nutrients of root layer of plantations and it is extremely necessary to get rid of it. Therefore it is planned to consider weed vegetation in terms of their biological composition and use, as indicated above, for enrichment of soil 
with nutrients and its disintegration;

Secondly, rains are very seldom in the republic during the summer period, therefore, considering the hot climate it is necessary to preserve available soil moisture. So in spring we must loose soil, cultivate or disk it up to depth of 12 to $15 \mathrm{~cm}$ with the aim to destruct soil capillaries. Later in summer grass flooring defends soil surface from sun rays and reduces evaporation and saves moisture;

Thirdly, during the cultivation season farm machines 15 - 20 times operate on the same row of plantings while executing technological operations. It leads to turning the top layer of the soil (at a depth of 4 to $5 \mathrm{~cm}$ ) into erosive mass (dead layer of soil horizon) and sealing it on the depth of up to 1.2 to $1.5 \mathrm{~m}$ This erosion layer of soil by plowing moves in the lower root-zone layers of the horizon, and from there better structured soil rises to the top. In the future under the influence of units' propulsions this layer also turns into erosive mass etc. So, from year to year this process is repeated. In the end the soil on the vineyards of the republic almost everywhere becomes "dead".

On territory of the sites the following types of weeds are identified: the asterisk (woodlouse- $B$. campestrist); wild cabbage; hare barley (H. Leporinum Link); Ling common (Malva L.); Abutilon Abans; cucumber field (wild); Polycnemum L.; bitterling hawkish; quinoa (Atriplex L.) [5] [6].

Let's take up woodlouse (asterisk) for example.

Description: flowers in period from May up to September, contains active substances Sano-Nina, vitamins E, C, carotene.

Drug use: applied to the sore spot for rheumatism, radiculitis, and sprains, wounds, used in homeopathy to treat gout.

Weed description shows that woodlouse is rather a herb than a weed and being mixed with soil turns into nutrient. Not all above mentioned plants may contain so many nutrients as woodlouse. It is necessary to investigate each of them in order to find out their composition. But the fact that these plants can play a positive role in preventing soil degradation is obvious.

To create herbal flooring of weeds between the rows of plantations we have designed an aggregate unit (Figure 1). The challenge was to save the thigh part of plant avoiding shred and lay it on the soil surface in the interrrows with its roots clipped. It is assumed that in the ranks of the plantings there will be tillage.

The instrument consists of a frame on which, two flat-cutting knives are installed with the help of the front and rear racks, fasteners, heels and central shoe. In front at the flat-cutting knives closure is set a chisel.

To the rear beam of the instrument by means of two tractions is hinged a band tyre of light weight construction (not shown); it's developed for a little packing of herbal flooring after cutting. The trip of band tyre into working and transport positions is performed by hydraulic cylinders.

The designed instrument works as follows. When moving along the interrows of vineyards flat cutting knives cut the weed vegetation at a depth of about $10-12 \mathrm{~cm}$ and place it on the soil surface, and the band tyre following it packs vegetation giving it a more condensed and systematized outlook.

In fact the working body of the unit is one big flat cutting paw with $2400 \mathrm{~mm}$ width. Tests in depth installation of the flat cutting knife adjustable by a screw mechanism have shown that at a small depth (8) installation there is a partial or complete interruption of movement of soil along the direction of motion through the surface

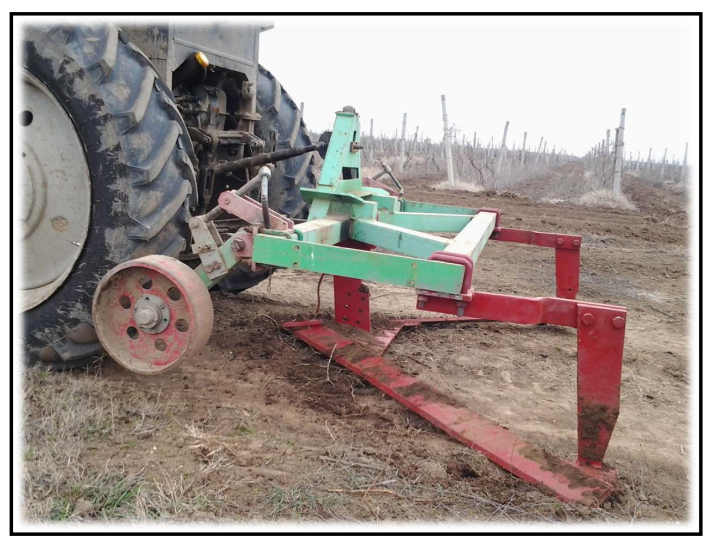

Figure 1. General view of prototype tool. 
of a knife. An optimal background soil movement through the surface of the knife was achieved with an installation depth of $12 \mathrm{~cm}$.

Comprehensive studies on the development of technical tools and carrying out agrotechnical measures for prevention of degradation processes in the vineyards of the republic will be continued.

\section{Conclusions}

1) Vineyards management held in the farms from year to year leads to the soil "necrosis", its transformation into a lifeless mass.

2) One of the main reasons that lead the soil deterioration to such deplorable state is absence of scientifically-grounded system of keeping rows of vineyards in proper order.

3) Proposed activities for the creation of herbal flooring (layer) are the integral part of the system of keeping the interrows of vineyards, which allows to prevent the degradation of soil, by moisture economy, reducing negative impacts of propulsion units on it, creating favorable conditions for vital functions of microorganisms and the root system of plants. These activities will lead to soil enrichment with nutrients and its disintegration and as a result, improve the productivity of crops and increase its fruiting term.

\section{References}

[1] Volkov, B.F. (1968) Soil Ecology of Agricultural Plants. Moscow, 207.

[2] Telegin, V.A., Gilev, S.D., Tsymbalenko, I.N. and Bastrykina O.S. (2013) Influence of Tillage Methods on the Littering of Culture in Corn-Steam Crop Rotation. Agriculture, 3, 27-29.

[3] Chupanov, M.A., Kaziev, M.-R.A. and Alichaev, M.M. (2012) The Positive Decision of Rospatent of the Russian Federation. System Maintenance of Vineyard Interrows. The applicant-State Scientific Institution of the Dagestan Research Institute of Agriculture, Application No. 2012141564/13, Appl. 28.09.2012.

[4] Petrov, V.S., Kuznetsov, G.Y. and Lukyanov, A.A. (2013) Perspective Way of Soil Maintaining in the Interrows of Vineyards. Winemaking and Viticulture, 3, 34-36.

[5] Buzoverov, A.V. (1998) Annual Herbs Is a Source of Organic Matter to the Soil of the Garden. Horticulture and Viticulture, 4, 9-10.

[6] Fisyunov, A.V. (1976) Handbook on Weed Control. Kolos, Moscow, 174. 
Scientific Research Publishing (SCIRP) is one of the largest Open Access journal publishers. It is currently publishing more than 200 open access, online, peer-reviewed journals covering a wide range of academic disciplines. SCIRP serves the worldwide academic communities and contributes to the progress and application of science with its publication.

Other selected journals from SCIRP are listed as below. Submit your manuscript to us via either submit@scirp.org or Online Submission Portal.
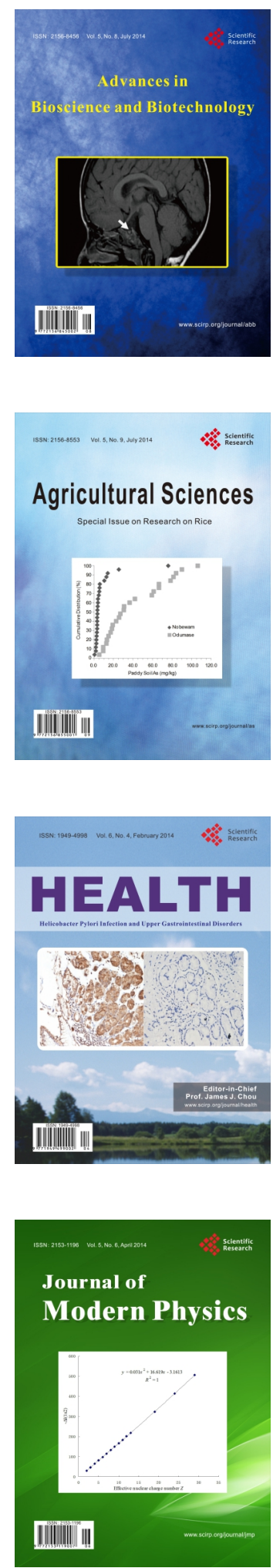
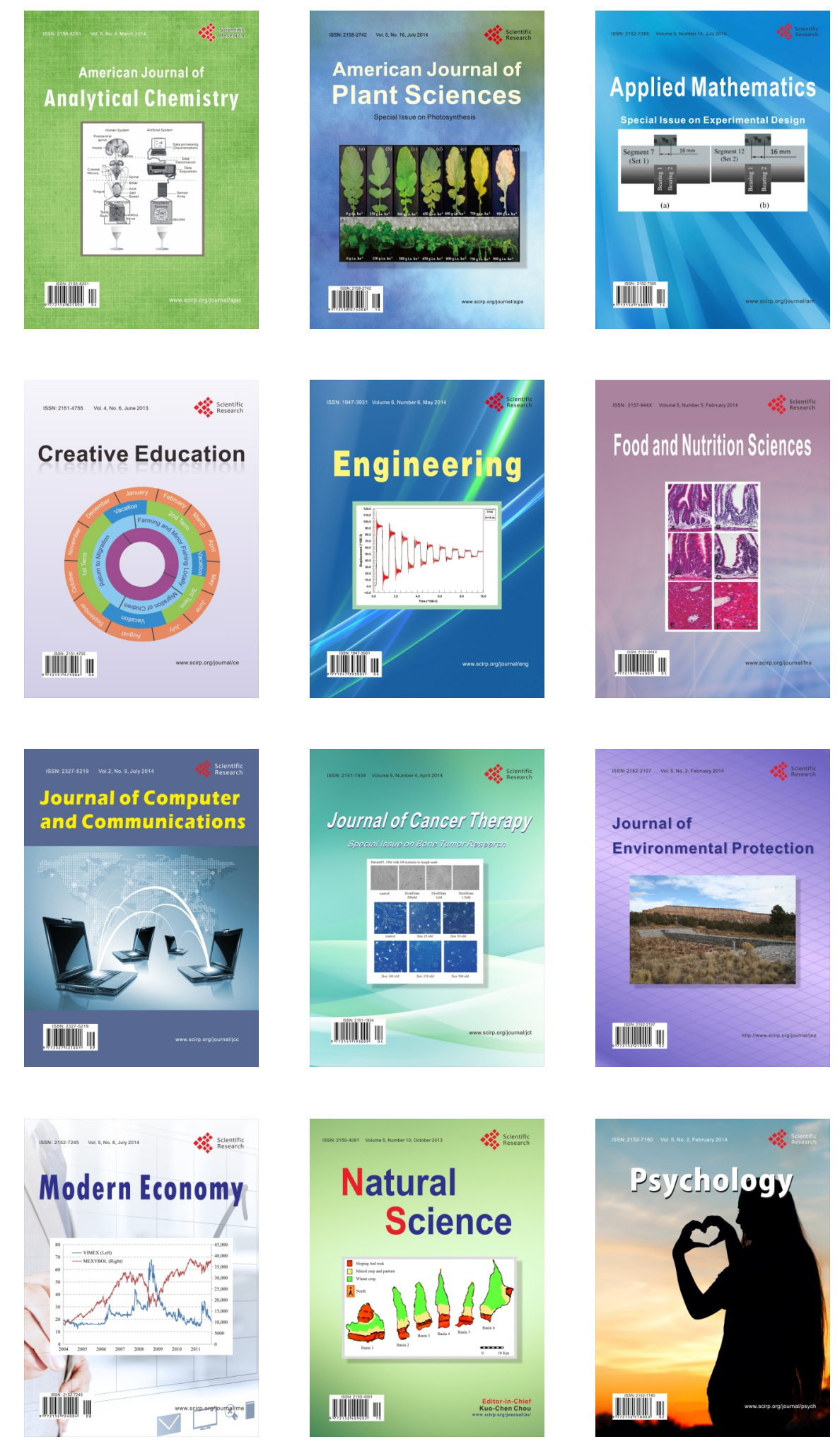